\title{
TAENIA SAGINATA IN MAN AND CYSTICERCOSIS IN CATTLE AND BUFFALOES IN ASWAN GOVERNORATE, EGYPT
}

By

\author{
AHMED K. DYAB ${ }^{1 *}$, MOHAMMED E. MARGHANY ${ }^{1}$, RAGAA A. OTHMAN ${ }^{1}$ \\ MAHMOUD A. AHMED ${ }^{2}$ AND OSAMA H. ABD-ELLA ${ }^{3}$ \\ Department of Medical Parasitology, Faculty of Medicine, Assuit University, \\ Department of Parasitology, Faculty of Veterinary Medicine, Aswan ${ }^{2}$ and Department \\ of Medical Parasitology, Faculty of Medicine, South Valley University ${ }^{3}$, Egypt. \\ ( ${ }^{*}$ Correspondence: ahmedsaf2001@yahoo.com or Ahmed2015@aun.edu.eg)
}

\begin{abstract}
Taeniasis is an important foodborne parasitic disease worldwide. This study determined the presence of cysticercosis in cattle and buffaloes and discussing their public health importance in Aswan Governorate, Upper Egypt. A total number of 45780 cattle, 223 buffaloes, were examined during the extended period from August 2015 till the end of July 2016. The existence of Cysticercus bovis infection among slaughtered Cattle and Buffaloes was studied at three different slaughterhouses (Aswan, Draw and Al-Sharq Al-Awsat) in Aswan Governorate. C. bovis in slaughtered cattle and buffaloes was $(7.5 \%$ \& $1.34 \%)$, respectively. Cattle and buffaloes infected with $C$. bovis it was for young and old animals, respectively $(7.5 \% \& 12.12 \%) ;(0.51 \% \&(7.14 \%)$. C. bovis in slaughtered cattle was commonly found in the tongue muscles $(70.46 \%)$, Heart $(2.8 \%)$, masseter muscles $(0.43 \%)$ and gluteal muscles $(0.29 \%)$. While for buffaloes heart $(100 \%)$ was the most common site infected with C.bovis .Moreover, Viable C.bovis was (86\%) in slaughtered cattle and buffaloes.

Taeniasis was detected in $(0.4 \%)$ of examined patients with gastroenteritis. The infection among male is $(1.5 \%)$ while it not detected in females. The results confirmed that cysticercosis is endemic among cattle and buffaloes in Aswan Governorate. Meat inspection is a must.
\end{abstract}

Keywords: Egypt, Aswan, Foodborne parasite, Cysticercosis, Taeniasis, Zoonosis

\section{Introduction}

Taenia saginata or beef tapeworm is one of the main sources of infection worldwide causing anorexia, weight loss, abdominal pain and digestive upset (Andreassen, 1998). The economic significance of $C$. bovis in the livestock industry may be considerable main ly in developing countries The downgrading and condemnation of the carcasses leads to substantial loss in livestock industry. Cattle and buffaloes represent the main reservoirs for zoonosis T. saginata (Hughes et al, 1993), affecting animal wealth, especially cattle, main source of meat, milk and hides in one of great economic importance. The parasitic diseases of humans and livestock are ubiquitous in the developing world and have substantial impacts on human welfare. For the estimated one billion people living in poverty who rely on livestock for their livelihoods, parasites steal valuable meat and its products resources by multiple pathways. This diversion of nutrients ultimately contributes to chronic malnutrition, greater human disease burdens and decreased productivity of livestock (Rist et al, 2015). Parasitic food borne diseases remain a major health problem affecting man and animals, particularly in the tropical and sub-tropical countries (Tagboto and Twonson, 2001).

Animal production is one of the vital sources of national income worldwide. In Egypt, with the rapid increased human population meat is the commonest animal protein for human consumption, so it should be parasites-free. The Cysticercus bovis within different tissues of cattle causes economic loss in the carcasses and threaten human health. $T$. saginata cysticercosis is one of the zoonotic parasites. It may be subjected to freezing in localized infection cases or total condemnation of carcasses and offal in generalized ones (Rossi et al, 2016). Requirements to increase demand of animal protein, which in turn based on raising buffaloes, cattle, camel, sheep and goats for meat and milk production. Such animals may suffer from parasitosis affecting their lives and/or 
production, either through direct or indirect adverse (Theodoropolous et al, 2002).

This study aimed to evaluate cysticercosis in cattle and buffaloes and to study morphologic characters of Cysticercus bovis and its effect on the tissue and investigate the zoonotic taeniasis in Aswan Governorate, Upper Egypt.

\section{Materials and Methods}

Locality: This is a descriptive study was carried out at three different slaughterhouses (Aswan city, Draw city and Al-Sharq Al Awsat in Abu-Simbuel Region) in Aswan Governorate, southern Egypt, during the period from August, 2015 to July 2016, to detect zoonotic taeniasis in Aswan Central Hospital.

Slaughtered animals: A total of 45780 cattle and 223 buffaloes slaughtered animals comprising from records of meat inspection in slaughterhouses were examined for the existence of larval stages. The slaughtered animals of different sex were considered as young below two years old, while adult above two years old. Imported animals were coming from Sudan. Moreover, seasonal variation was recorded.

Samples collection and postmortem examination: Routine post mortem inspection to heart, tongue diaphragm, liver, kidneys, lung, esophagus, and masseter muscles as well as shoulder muscles and inspection to gluteal, omentum, mesentery. Cysts were carefully removed from condemned organs without injuries to their walls. All $C$. bovis were collected in separate labeled bags kept in an ice box container and transported to the Parasitology Department, Aswan Faculty of Veterinary Medicine.

Macroscopic examination and fertility of C. bovis: Cysts were macroscopically examined and classified as viable or degenerating after fingers pressing. Translucent, fluid filled bladder viable cysts were considered mature when contained protoscolex. Those without a distinct protoscolex were imamture. Degenerating cysts were classified as calcified when their contents were solid, as cheesy when smooth, or dull when they contained nothing and were apparently neither viable nor degenerating for criteria of viable cyst (Fahmy et al, 2015). C. bovis was microscopically examined fixation and stained with acetic acid alum carmine stain and/or hematoxylin and eosin (Bancroft and Gamble, 1997). SEM of cysts was done after Bozzola and Russell (1991).

Detection of taeniasis in human: Stool samples were collected from 325 patients males and 124 females suffering from gastrointestinal disturbances, who attended Aswan Central Hospital. Each sample (10g) was collected in clean labeled plastic container with Snap-on lids and transported ed Department of Parasitology, Aswan Faculty of Medicine. Samples were fixed in $10 \%$ formalin saline solution in a ratio of 3:1 part farces and stored in labeled vials at room temperature until examination. Stool samples were examined microscopically by direct smear and simple sedimentation techniques (Urquhart et al, 1994).

Statistical analysis: Data were tabulated, computerized and analyzed using SPSS (Statistical Package for Social Science) program for statistical analysis. Data were entered as numerical or categorical, as appropriate. Two types were used: Descriptive statistics: Qualitative data were expressed as frequency and percent at $95 \%$ confidence interval (95\% CI). Analytical statistics: Chi-square test was used to measure the association between qualitative variables. $\mathrm{P}$ value was significance if less than 0.05 .

\section{Results}

In the present study, taeniasis was among $325(0.4 \%)$ among patients examined by sedimentation technique. Cysticercus bovis in slaughtered animals was $(7.5 \%$ \& $1.34 \%)$ among cattle and buffaloes, respectively. $C$. bovis was $(7.5 \%$ \& $12.12 \%)$ and $(0.51 \%$ \& $7.14 \%$ ) in young and old animals, respecttively. The highest $C$. bovis infection in cattle and buffaloes was during winter $(9.4 \%$ $\& 4.25 \%$ ) respectively. In cattle, tongue, 
heart, masseter muscles and gluteal muscle were $C$. bovis the most predilection organs, but in buffaloes was found only in the heart. In the present study, macroscopically $C$. bovis was small, pea-sized oval in shape, translucent with a single white scolex about $1.0 \mathrm{~cm}$ in diameter, and filled with clear fluid. Details are given in figures $(1,2,3,4$, $5 \& 6)$.

\section{Discussion}

In the present work, taeniasis among 325 patients was $(0.6 \%)$, which was lower than $0.75 \%$ reported in Mexico (Martinez-Maya et al, 2003) and in Turkey (Culha, 2006). The differences may be due to study location, personal hygiene, educational level, and eradication programs. The infection rate was $(1.6 \%)$ in males, but none in females. In Egypt, Taenia saginata was among the commonest intestinal parasites that caused chronic digestive disorders as persistent diarrhea, chronic abdominal pain and/or blood in the stool (Omran and Mohammad, 2015).

In the present study, $C$. bovis was $3433 /$ $45780(7.5 \%)$ among cattle at three different slaughterhouses in Aswan Governorate. This agreed with Elkhtam et al. (2016) reported $6.09 \%$ in Menofia Governorate, as well as abroad in Brazil, (Almeida et al, 2002), Vietnam (Van De et al, 2014) in 23 European countries (Laranjo-González et al, 2016), and in Ethiopia (Engdaw et al, 2015; Wondimagegnei and Belete, 2015; Jemal and Kebede, 2016), however, Dada (1980) reported $0.9 \%$ in Sudan. These data were higher than that $2.16 \%$ in Zimbabwe (Pugh and chambers, 1989; Phiri, 2006) in Zambia and by Abu-Elwafa and Al-Araby (2008), Basem et al. (2009) in Egypt, Ofukwu et al. (2009), Rabi'u and Jegede (2010), Ngwu et al. (2004) in Nigeria, Kozłowska-Łój (2012) in Poland, Dupuy et al. (2014) in France, Dorny et al. (2009) in Belgium and Rossi et al. (2016) in Brazil. On the contrary, the present data was lower than $(20 \%)$, reported by Abdel-Hafeez et al. (2015) in Egypt, Mosienyane (1986) in Botswana, Kebede (2008), and Abunna et al. (2008) in Ethio- pia. In the present study, $C$. bovis was in $(9.3 \%)$ imported cattle and $(0.37 \%)$. Indigenous ones. This agreed with Haridy et al. (1999) in Egypt and Opara et al. (2006) in Nigeria. The lower prevalence of cysticercosis in indigenous ones might be due to continuous activities the Egyptian Veterinary Medical Authorities.

In the present study, in buffaloes $C$. bovis was $223(1.34 \%)$. This more or less agreed with $(0.8 \%)$ in Assiut Governorate (Basem et al, 2009), and more than $(0.14 \%)$ in Greater Cairo Governmental Slaughterhouse (Haridy et al, 1999) and in India Pramanik et al. (1984).

C. bovis in cattle and buffaloes varied were $(7.46 \%$ \& $0.97 \%)$ in males and $(17.7 \%$ $\&(5.5 \%)$ in females, with significant differences among sex of cattle and buffaloes $(\mathrm{P}<0.05)$. As to ages, cysticercosis in cattle and buffaloes above 2 years old animals were higher and then less than 2 years. This agreed with Pramanik et al. (1984), Okolo (1986), Dorny et al. (2000), Basem et al. (2009) and Opara et al. (2006). The highest infection of $C$. bovis in cattle and buffaloes was during winter $(9.4 \% \& 4.25 \%)$, which in cattle began to decline slightly in spring $(8.9 \%)$, followed by summer and autumn $(6.02 \%$ \& $5.25 \%)$ respectively, but without significant differences $(\mathrm{P}>0.05)$. Seasonal variation might be due to blood kinetics and daily activities, the environmental factors affect blood kinetics that affect onchosphers distribution and hence the predilection sites.

In the present study, $C$. bovis in cattle were in tongue $(70.46 \%)$, heart $(28.8 \%)$, masseter muscles $(0.43 \%)$ and the gluteal muscles $(0.29 \%)$. In buffaloes, C. bovis was only in heart $(100 \%)$, with significant differences of sites in slaughtered cattle $(\mathrm{P}<0.05)$ but not in buffaloes. This agreed with Okolo (1986), Haridy et al. (1999), Opara et al. (2006), Abunna et al. (2008), Kebede (2008) and Basem et al. (2009). The variations in the predilection sites may be attributed to the animal different practices in such areas like using them daily in the many 
different agricultural activities, which influenced the cysticerci distribution sites.

\section{Conclusion}

The outcome data confirmed that cysticercosis is endemic among cattle and buffaloes. Eradication of bovine cysticercosis required cooperation between the public health and official veterinary authorities. Public health education is the key factor for control of taeniasis and cysticercosis. Meat inspection is recommended than routine inspection and diagnosis of human taeniasis and treatment is also recommended to cut he life cycle.

Conflict of Interest: The authors declared no conflict of interests.

\section{Acknowledgment}

This project was kindly funded by the Research Grant (\#1237) from Faculty of Medicine, Assiut University, Egypt

\section{References}

Abdel-Hafeez, EH, Kamal, AM, Abdelgelil, NH, Abdel-Fatah, M, 2015: Parasites transmitted to human by ingestion of different types of meat, El-Minia City, El-Minia Governorate, Egypt. J. Egypt Soc. Parasitol. 45, 3:671-80.

Abu-Elwafa, SA, Al-Araby, MA, 2008: Prevalence of tissue parasites among slaughtered animals in Dakahlia Governorate, Mansoura J. Vet. Med. 10, 1:79-91.

Bunna, F, Tilahun, G, Megersa, B, Regassa, A, Kumsa, B, 2008: Bovine cysticercosis in cattle slaughtered at Awassa municipal abattoir, Ethiopia: Prevalence, cyst viability, distribution and its public health implication. Zoon. Publ. Hlth. J. 55, 2: 82-8.

Almeida, LPD, Moreira, MD, Reis, DO, Santos, WL, 2002: Cisticercose bovina: um estudo comparativo entre animais abatidos em frigorificcos com serviço de inspeçäo municipal. Hyg. Aliment. 16, 99:51-5.

Andreassen, J, 1998: Intestinal tapeworms. In: Topley \& Wilson's, Microbiology and Microbial Infection, $9^{\text {th }}$ ed., Oxford University Press Inc., New York.

Basem, RNA, Syed, ASM, Hussain, AA, Arafa, MI, 2009: Occurrence of cysticercosis in cattle and buffaloes and Taenia saginata in man in Assiut Governorate, Egypt. Egypt. Vet. World J. 2, 5:173-6.

Buchy, P, 2003: Intestinal parasitoses in the Mahajanga Region, west coast of Madagascar.
Bull. Soc. Pathol. Exot. 96, 1:41-5.

Culha, G, 2006: The distribution of patients with intestinal parasites presenting at the Parasitology Laboratory of the Mustafa Kemal University Medical Faculty. Turk. Parazitol. Derg. 30, 4:302-4.

Dada, BJ, 1980: Taeniasis, cysticercosis and echinococcosis/hydatidosis in Nigeria: I- prevalence of human taeniasis, cysticercosis and hydatidosis based on a retrospective analysis of hospital records. J. Helminthol. 54, 4:281-6

Dorny, P, Vercammen, F, et al, 2000: Seroepidemiological study of Taenia saginata cysticercosis in Belgian cattle. Vet. Parasitol. J. 88, 1:43-9.

Dorny, P, Praet, N, Deckers, N, Gabriel, S, 2009: Emerging food- borne parasites. Vet. Parasitol. J. 163, 3:196-206

Dupuy, C, Morlot, C, Demont, P, Ducrot, C, Calavas, D, et al, 2014: Construction of standardized surveillance indicators for bovine cysticercosis. Prevent. Vet. Med. J. 115, 3/4: 288-92.

Elkhtam, AO, Mostafa, IA, Shawish, RR, 2016: Prevalence and economic impact of Cysticercus bovis in slaughtered cattle in Menoifia Governorate, Egypt. Alex. Vet. Sci. J. 50, 1: 130-4.

Engdaw, TA, Alemneh, AT, Ambaw, ST, 2015: Study on the prevalence of Cysticercus bovis in Kombolcha Elfora, North-Eastern Ethiopia. Euro Appl. Sci. J. 7, 4:152-7.

Fahmy, HA, Khalifa, NO, El-Madawy, RS, Afif, JSA, Aly, NSM, et al, 2015: Prevalence of bovine cysticercosis and Taenia saginata in man. Glob. Vet. J. 15, 4:372-80.

Haridy, FM, Ibrahim, BB, Morsy, TA, Ramadan, NI, 1999: Human taeniasis and cysticercosis in slaughtered cattle, buffaloes and pigs in Egypt. J. Egypt Soc. Parasitol. 29, 2:375-94.

Hughes, G, Hoque, M, Tewes, MS, Wright, S H, Harrison, LJ, 1993: Seroepidemiological study of Taenia saginata cysticercosis in Swaziland. Res. Vet. Sci. 55, 3:287-91

Jemal, D, Kebede, B, 2016: The study of major parasitic causes of organ condemnation and financial losses in cattle slaughtered at Hawassa Municipal Abattoir, Ethiopia. Cogent. Food Agricul. J. 2, 1:1-12.

Kebede, N, 2008: Cysticercosis of slaughtered cattle in northwestern Ethiopia. Vet. Sci. J. 85, 3:522-6.

Kozlowska-Łój, J, 2012: Prevalence of cysticercosis in cattle and pigs in the Lublin province 
in the years 2005-2008. Wiad Parazytol. J. 57, 3:193-4.

Laranjo-González, M, Devleesschauwer, B, Gabriël, S, Dorny, P, Allepuz, A, 2016: Epidemiology, impact and control of bovine cysticercosis in Europe: A systematic review. Parasit. Vect. J. 9, 1:1-12.

Martinez-Maya, JJ, de Aluja, AS, Avila-Ramírez, G, Aguilar-Vega, L, Plancarte-Crespo, A, et al, 2003: Taeniasis and detection of antibodies against Cysticercus among inhabitants of a rural community in Guerrero State, Mexico. Salud. Publ. de Mexico 45, 2:84-9.

Mosienyane, MG, 1986: A survey of Cysticercus bovis (measles) infestation in cattle sent for slaughter to Botswana Meat Commission (BMC): A ten years retrospective study-19741983." Int. J. Zoon. 13, 2:124-30.

Ngwu, GI, Ohaegbula, AB, Okafor, FC, 2004: Prevalence of Fasciola gigantica, Cysticercus bovis and some other disease conditions of cattle slaughtered in Nsukka Urban Abattoir. Anim. Res. Int. J. 1, 1:7-11.

Opara, MN, Ukpong, UM, Okoli, IC, Anosike, JC, 2006: Cysticercosis of slaughter cattle in south eastern Nigeria. Ann. NY Acad. Sci. J. 10, 81:339-46.

Okolo, MI, 1986: Studies on Taenia saginata cysticercosis in eastern Nigeria. Int. J. Zoon. 13, 2:98-103.

Ofukwu, RA, Akwuobu, CA, Okwori, AI, 2009: Epidemiology and public health importance of bovine cysticercosis in Makurdi, NorthCentral Nigeria. Tanzania Vet. J. 26, 1:37-42.

Omran, EK, Mohammad, AN, 2015: Intestinal parasites in patients with chronic abdominal pain J. Egypt. Soc. Parasitol. 45, 2:389-96

Pugh, KE, Chambers, PG, 1989: Observations on Cysticercus bovis in slaughter cattle in Matabeleland Province, Zimbabwe. Vet. Rec. J. 125, 19:480-4.

Phiri, AM, 2006: Common conditions leading to cattle carcass and offal condemnations at 3 abattoirs in the western Province of Zambia and their zoonotic implications to consumers. S. Afr. Vet. Assoc. J. 77, 1:28-32.

Pramanik, AK, Bhattacharyya, HM, Sengupta, DW, 1984: Occurrence of C.bovis in slaughtered cattle and buffaloes in Calcutta and its public health significance. Indian Anim. Hlth. J. 23, 2:141-6.

Rabi'u, BM, Jegede, OC, 2010: Incidence of bovine cysticercosis in Kano State, Northwestern, Nigeria. Bayero Pure Appl. Sci. J. 3, 1:00-3.

Rist, CL, Garchitorena, A, Ngonghala, CN, Gillespie, TR, Bonds, MH, 2015: The burden of livestock parasites on the poor. Trends Parasitol. J. 31, 11: 527-30.

Rossi, GAM, De Simoni, HAS, Lopes, WDZ, Almeida, HM, Soares, VE, et al, 2016: Prevalence and geospatial distribution of bovine cysticercosis in the state of Mato Grosso, Brazil. Prev. Vet. Med. J. 130: 94-8.

Tagboto, S, Townson, S, 2001: Antiparasitic properties of medicinal plants and other naturally occurring products. Adv. Parasitol. J. 50: 199-209.

Theodoropoulos, G, Theodoropoulou, E, Petrakos, G, Kantzoura, V, Kostopoulos, J, 2002: Abattoir condemnation due to parasitic infections and its economic implications in the region of Trikala, Greece. Vet. Med. Infect. Dis. Vet. Publ. Hlth. J. 49, 6:28-4.

Urquhart, GM, Armour, J, Duncan, JL, Jennings, EW, Dunn, AM, 1994: Veterinary Parasitology. Longman Singapore Publishers Ltd, Singapore.

Van De, N, Le, TH, Lien, PT, Eom, KS, 2014: Current status of taeniasis and cysticercosis in Vietnam. Korean Parasitol. J. 52, 2:125-9.

Wondimagegnei, K, Belete, S, 2015: Prevalence and public health significance of Cysticercus bovis in and around Debreberhan City. Euro Appl. Sci. J. 7, 5:199-208.

\section{Explanation of figures}

Fig.1: Tongue of a cattle showing white nodules scattered throughout the tongue muscles (arrowheads, inset), caused by Cysticercus bovis of Taenia saginata. Bar $=1.5 \mathrm{~cm}$.

Fig.2: Heart of a steer showing white nodule in myocardium (arrowheads, inset), caused by the Cysticercus bovis of Taenia saginata (beef measles) $\mathrm{Bar}=1.5 \mathrm{~cm}$

Fig. 3: Photomicrograph of acid alum carmine staining of cattle tongue. Magnification(x10), showing a cavity containing Cysticercus bovis (arrow) surrounded by a fibrous capsule (asterisk) with an intense inflammatory reaction rich in eosinophilic polymorph nuclear leukocytes Fig. 4: Photomicrograph of an H\&E staining of cattle tongue. Magnification(x10), showing a cavity containing Cysticercus bovis (arrow) surrounded by a fibrous capsule (asterisk) with an intense inflammatory reaction rich in eosinophilic polymorph nuclear leukocytes Fig. 5: Cysticercus bovis prepared with Acid carmine stain, showed invaginated inverted scolex (arrow). X 10.

Fig. 6: SEM, Cysticercus bovis scolex with suckers, embedded between heart muscles.-Viable C. bovis in different infected organs in cattle and buffaloes $(86 \%)$ while dead cyst $(13.9 \%)$. 

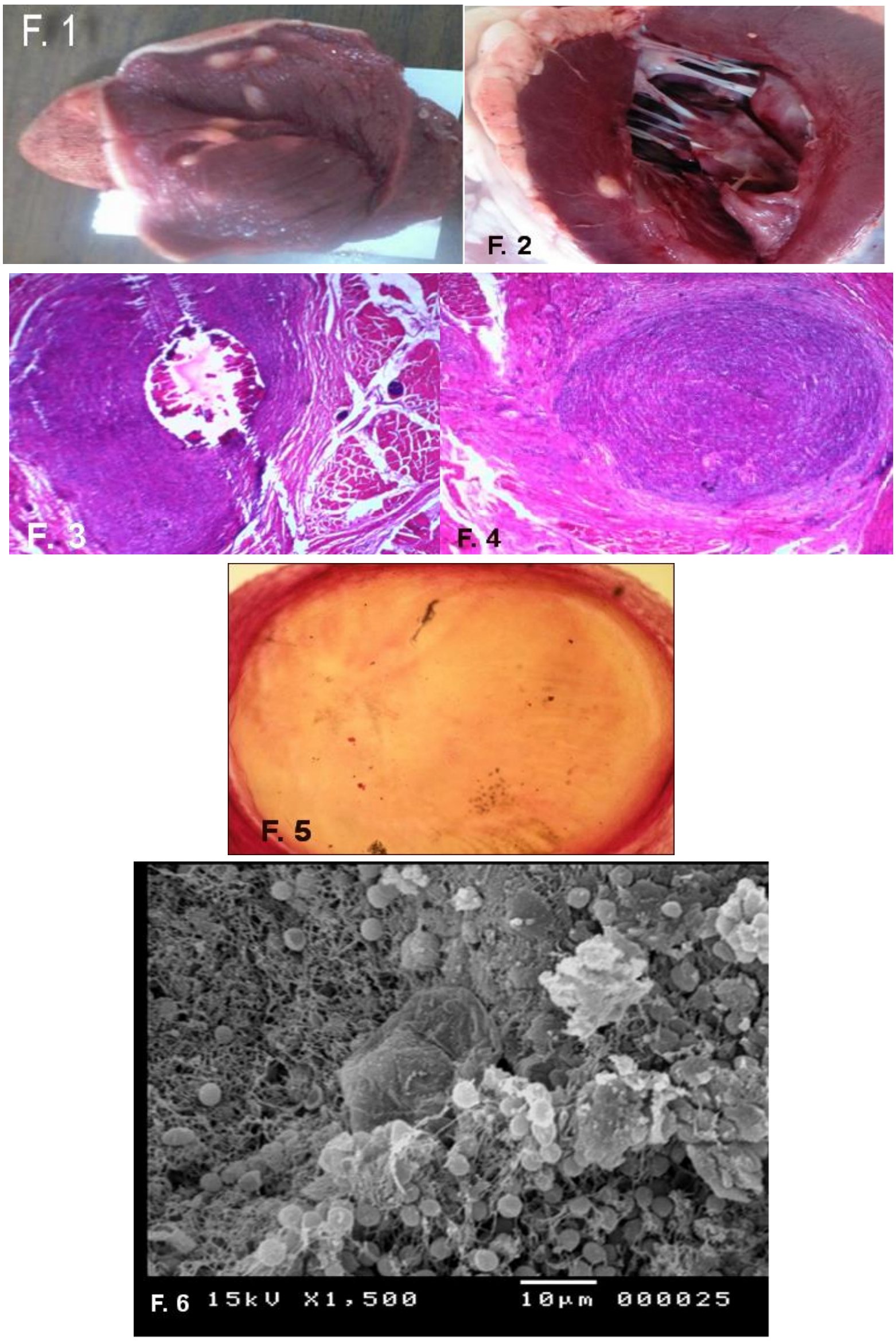